\title{
A New Method for Reinforcing Concrete Rectangular Section Columns
}

\author{
Xiantao Zeng ${ }^{1 *}$ and Zhenhua Ren ${ }^{2}$ \\ ${ }^{1}$ Hunan Institute of Engineering, China \\ ${ }^{2}$ CIC of Wind Power Equipment and Energy Conversion, China
}

*Corresponding author: Xiantao Zeng, Hunan Institute of Engineering, China.

Received Date: June 01, 2019

Published Date: June 17, 2019

\begin{abstract}
This paper presents a new method for the reinforcement of a rectangular section concrete column by bidirectional prestressed angle steel plates. The rectangular section column is divided into an upper reinforcement section, an axial prestressed elevation section and a lower reinforcement section. Four angle steel plates are installed in the upper and lower reinforcement sections, and the concrete columns are reinforced with circumferential prestressing. In the axial prestressing jacking section, axial prestressing angle steel plates mounted on the upper and lower reinforcing sections are axially prestressed by axial prestressing jacking bolts. A preliminary experimental analysis shows that the load capacity of the concrete column after reinforcement is $2-5$ times that of the original concrete column. The implementation of the new method does not affect the use of the concrete column and does not damage its structure, and the pre-stress can be adjusted to ensure that the original structure and the reinforcement structure layer are stressed synchronously. The failure mode of the concrete in the column changes from brittle failure to plastic failure, and the stiffness, ductility and seismic resistance of the column are obviously improved after the reinforcement.
\end{abstract}

Keywords: Two-way prestressing; Angle steel plate; Reinforcement; Concrete rectangular section column; New method

\section{Introduction}
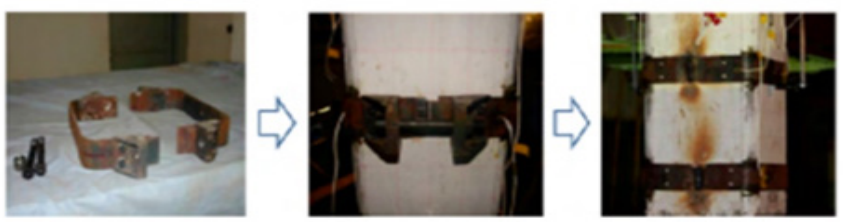

Figure 1: Prestressed steel hoop reinforcement of a concrete rectangular section column.

Reinforced concrete structures are very widely used, but many reinforced concrete structures need to be additionally reinforced due to construction quality problems, functional changes, structural overload, and exposure to harsh environments. Concrete column reinforcement methods include the enlarged section method, spiral hoop constrained column method, outer steel method, fibrereinforced polymer reinforcement method, axial prestressed strut method, axial prestressed tie rod method, transverse prestressed reinforcement method and axial prestressed reinforcement method. Lateral prestressing reinforcement methods include the use of a low prestressed steel hoop or steel strand reinforcement [1-8], as shown in Figure 1. A steel hoop or steel strand can effectively restrain the deformation of concrete, control the generation and development of cracks, and significantly improved the bearing capacity and seismic performance of the column. Due to the constraint and friction at the corners, the corner prestress loss of the rectangular steel hoop plate is more than $10 \%$ during the tensioning process (Figure 1).

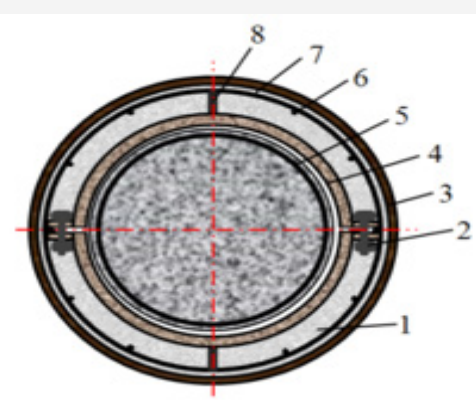

1- Post-casting protective concrete; 2-Bolts; 3-Template; 4Semicircular steel casing;

5- Reinforced column concrete; 6- Structural rib; 7-Ring construction hooping; 8- Stud or footboard

Figure 2: Prestressed steel hoop reinforcement of a concrete rectangular section column. 
The author invented the "pre-stressed steel casing and the reinforcement of a section to strengthen a concrete column method" [9]. The method changes the concrete from a two-directional stress state to a three-directional force state, and the strength and rigidity of the column are improved. Figure 2 is a cross-sectional view of the reinforcement column(Figure 2).

The axial prestressing reinforcement methods include the axial prestressed strut method and the axial prestressed tie rod method. The prestressed pulling and pressing rods increase the pressure of the pressed part of the concrete column; the external pulling and pressing bars are not synchronized with the original tensile reinforcement in the concrete column, and there may be stepwise damage. To improve the reinforcement effect on the column, Huang Chunhua [10] carried out the "two-direction pre-stressing method to reinforce a concrete column with a high axial compression ratio". The prestressed strut method is combined with a prestressed steel hoop to reinforce the "high axial compression ratio column". The results show that the method has a strong unloading effect on the axial force column and causes a large increase in the bearing capacity. After the reinforcement, the plastic deformation capacity and hysteretic energy performance of the column are increased, and the ductility and seismic performance of the column are improved.

\section{Introduction to the New Reinforcement Method}

The new method divides the reinforced concrete rectangular section column into an upper reinforcement section, an axial prestressed elevation section and a lower reinforcement section. Four prestressed angle steel plates are installed on the upper and lower reinforcing section columns, and the concrete columns are circumferentially prestressed by the flanges on the angle steel plates. In the axial prestressing jacking section, axial prestressing is applied to the angled steel plates of the upper and lower reinforcing sections by jacking bolts. The four sides of the four angle steel plates are provided with flanges; the flanges parallel to the axial direction of the angle steel plate are called axial flanges, and the flanges perpendicular to the axial direction of the angle steel plate are called circumferential flanges. A rectangular steel cylinder is formed by pulling the axial flange on the angle steel plate and fastening it, and two-directional pre-stress reinforcement is applied to the upper section and lower reinforcement section, as shown in Figure 3 (Figure 3).

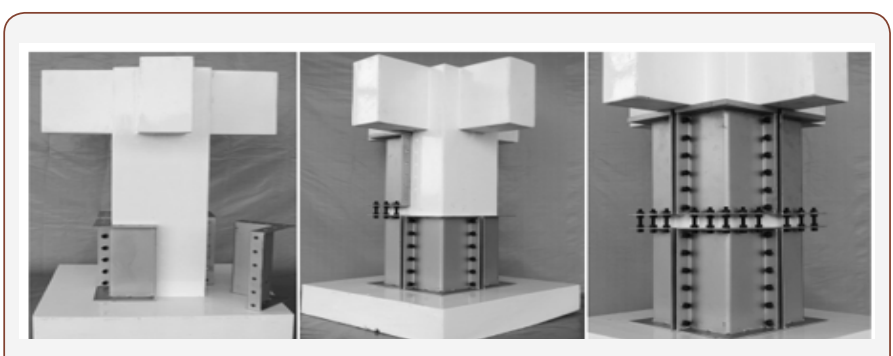

Figure 3: Model of reinforcement of two-direction prestressed angle steel plate with a rectangular section column.

The axial prestressing jacking device consists of a set of screw rods with two nuts on the screw rods. Corresponding to each screw rod, the angled steel plate has a hole in the circumferential flange, and the screw rod is inserted into the circumferential flange hole of the upper and lower reinforcing angle steel plates. The two nuts are in the axial prestressed jacking section, and the two nuts are rotated in opposite directions, so that one nut is brought up and one nut brought down to contact with the circumferential flange of the angle steel plates to exert an axial prestress on the two steel cylinders formed by the upper and lower rectangular angle steel plates. The cross-section of the column after reinforcement is shown in Figure 4 (Figure 4).

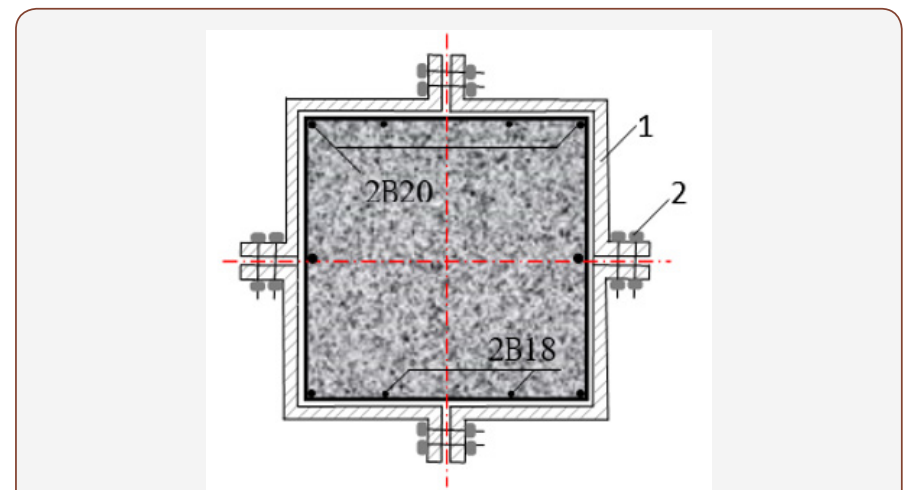

1-Angle steel plate; 2-Bolt

Figure 4: Sectional view of concrete column after angle steel plate reinforcement.

After the two-directional prestressing is applied, a reinforced concrete protective layer is cast on the outer surfaces of the upper and lower rectangular steel cylinders, as shown in Figure 5. There is a steel skeleton in the reinforced concrete protective layer that is composed of radial steel bars and peripheral stirrups. The radial steel bars are arranged perpendicular to the surface of the angle steel plate. One end is welded to the surface of the angle steel plate, and the other end is welded with a surrounding stirrup. Concrete is poured in the vertical template outside of the stirrup to form a new concrete column (Figure 5).

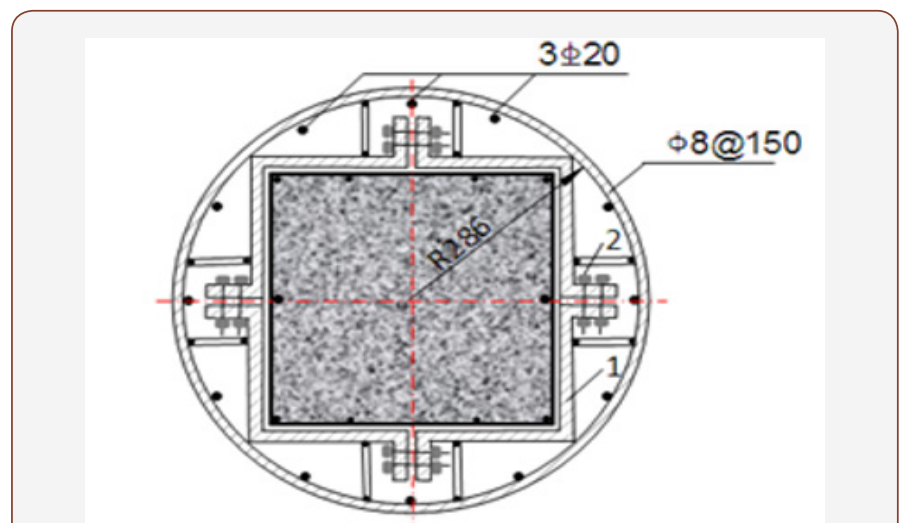

Figure 5: Schematic diagram of protective layer construction.

\section{Conclusion}

The new "two-directional prestressed angle steel plate without damage and reinforcement of rectangular section concrete column method" obtained a Chinese invention patent in 2018. The method is simple in construction and convenient in operation and has the following characteristics: 
1. The new method implements two-directional prestressing reinforcement on the concrete column, and the prestressing amount is adjustable.

2. The existence of an adjustable pre-stress ensures that the original structure and the reinforcement structure are synchronized in force and that there is no step damage.

3. The new method does not damage the structure of the original concrete column and does not reduce its bearing capacity.

4. There is a certain matching relationship between the two directions of the prestressing, so that the bearing capacity of the concrete column after reinforcement can reach the optimal value.

5. The new method not only improves the strength and rigidity of the column but also improves the seismic performance.

6. Reinforcement construction does not require the unloading of the original concrete column and does not affect the use of the structure. The reinforcement construction can be carried out in-operation, and the structure can be immediately bear load after reinforcement.

7. When only the circumferential prestressing is applied, the bearing capacity of the concrete column is twice as large as that before the reinforcement, and the bearing capacity of the two-directional prestressing is up to 5 times that before the reinforcement [11].

8. The research shows that the bearing capacity of the twodirectionally prestressed concrete column is higher than the sum of the bearing capacity of the corresponding steel pipe column and the bearing capacity of the concrete column; the technical effect of the application of bidirectional prestressing is not a simple superposition of the two [11].

\section{Acknowledgment}

This work was supported by the National Natural Science Foundation of China (Grant No. 51678430, China Postdoctoral
Science Foundation(Grant No.2016M591707),The natural science foundation of Hunan Province(Grant No.2017JJ4016,2018JJ4042).

\section{Conflict of Interest}

No conflict of interest.

\section{References}

1. Guo Zixiong, Huang Qunxian, Liu Yang, Mei Z (2016) Prestressed steel jacket for retrofitting reinforcement concrete column [J]. Engineering Mechanics 33(3): 1-9.

2. Zhang Xuezhao (2014) Experimental study and engineering application of axial compression of concrete cylinders strengthened by a transverse prestressed steel strip [D]. Xian University of Architecture and Technology.

3. Hao Liangjin (2014) Experimental study on axial compression performance of prestressed steel strip reinforced concrete columns [D]. Xian University of Architecture and Technology.

4. Zhang Bo, Yang Yong, Liu Yi, Hao LJ (2016) Experimental study on axial compression performance of reinforced concrete columns strengthened with prestressed steel strips [J]. Engineering Mechanics 33(3): 104-111.

5. Wang Hai-dong, Zhou Liang, Deng Pei-hang, Sheng WC (2014) Seismic performance of RC columns confined by low prestressed steel belts [J]. Journal of Hunan University (Natural Science) 41(2): 19-25.

6. Zhao Yong (2014) Experimental study on axial compression performance of prestressed steel strip confined concrete square column [D]. Xian University of Architecture and Technology.

7. Zhu Juntao, Wang Xinling (2015) Experimental study on compression performance of damaged concrete columns with CFRP strips [J]. Earthquake Resistant Engineering and Retrofitting 01: 100-105.

8. Guo Junping, Deng Zongcai, Lin Jinsong (2014) Experimental study on seismic behavior of RC columns strengthened with prestressed high strength steel wire mesh [J]. Journal of Building Structures 35(2): 128136.

9. Ren Zhenhua, Zeng Xiantao, Qu Wenjun (2018) Study on axial bearing capacity of reinforced concrete short columns strengthened by prestressed steel retaining tube [J], Earthquake Resistant Engineering and Retrofitting 1: 89-97.

10. Huang Chunhua (2009) Study on the reinforcement of concrete columns with a high axial compression ratio by the two-direction prestressing method [D], Guangdong University of Technology.

11. Ren Zhenhua, Zeng Xiantao, QU Wenjun (2016) The analysis of axial bearing capacity of concrete rectangular short column strengthened with pre-stressed angle steel plate [J], International Conference on Innovative Production and Construction (IPC2016) 29-30: 321-328. 